\title{
Re-thinking water policy priorities in the Mediterranean region in view of climate change
}

\author{
Ana Iglesias , Luis Garrote , Agustin Diz , Jeremy Schlickenrieder , \\ Francisco Martin-Carrasco
}

Department of Agricultural Economics and Social Sciences, Universidad Politécnica de Madrid, Spain

Department of Hydraulic and Energy Engineering, Universidad Politécnica de Madrid, Spain

\begin{abstract}
A B S T R A C T
Water is scarce in Mediterranean countries: cities are crowded with increasing demand; food is produced with large amounts of water; ecosystems demand more water that is often available; drought affects all. As climate change impacts become more noticeable and costlier, some current water management strategies will not be useful. According to the findings of CIRCE, the areas with limited water resources will increase in the coming decades with major consequences for the way we produce food and we protect ecosystems. Based on these projections this paper discusses water policy priorities for climate change adaptation in the Mediterranean. We first summarise the main challenges to water resources in Mediterranean countries and outline the risks and opportunities for water under climate change based on previous studies. Recognising the difficulty to go from precipitation to water policy, we then present a framework to evaluate water availability in response to natural and management conditions, with an example of application in the Ebro basin that exemplifies other Mediterranean areas. Then we evaluate adaptive capacity to understand the ability of Mediterranean countries to face, respond and recover from climate change impacts on water resources. Social and economic factors are key drivers of inequality in the adaptive capacity across the region. Based on the assessment of impacts and adaptive capacity we suggest thresholds for water policy to respond to climate change and link water scarcity indicators to relevant potential adaptation strategies. Our results suggest the need to further prioritise socially and economically sensitive policies.
\end{abstract}

Keywords:

Mediterranean

Climate change

Water policy

Adaptation and assessment

\section{Introduction}

\subsection{Challenges to water resources in the Mediterranean}

Mediterranean countries are diverse from various points of view including their socio-economic development, climate, water availability, infrastructure levels, or social and ecological resources. However, the region as whole is undergoing rapid social and environmental changes which may harbour negative implications for current and future sustainability.
This is particularly true for the Mediterranean water sector where pressures and impacts on water scarcity are projected to multiply under climate change. Water scarcity often results in conflicts among users which are compounded by complex institutional and legal structures that threaten the development of policies geared towards sustainable management (Iglesias et al., 2007a).

A number of studies have shown that under climate change annual iver flow is expected to decrease in Southern Europe and increase in Northern Europe; changes are also expected in 
the seasonality of river flows with considerable differences over the European region (Arnell, 2004; Milly et al., 2005; Alcamo et al., 2007). Nevertheless many of these projections do not take into account the effects of policy. One alternative measure that has been used to include some policy aspects is the water exploitation index, which is calculated annually as the ratio of total freshwater abstraction to the total renewable resource (Raskin et al., 1997). But even though the WEI can provide additional information regarding runoff, such an analysis still struggles to fully reflect the level of available water resources.

In many countries throughout the region, water demand already exceeds water availability - such a situation imposes a strain on ecosystems and indicates the need for a policysensitive approach (Iglesias et al., 2007b; Yang and Zehnder, 2002; Hoff, 2010). The average annual potential water availability per capita considering the total freshwater resources in southem Mediterranean countries is less than $1000 \mathrm{~m}^{3}$ per capita and year (Table 1). In countries like Egypt, [srae], and Libya, demand is above the available resources, and water scarcity crises are common (Table 1). The difficulty in forecasting highly variable rainfall multiplies the challenges faced by water resource managers and increases the likelihood of water conflicts.

The region's overall socio-economic model places available water resources under considerable stress. In many cases, agriculture is responsible for water imbalances because it accounts for more than $50 \%$ of water use in most countries (FAO, 2008). Thus, other economic uses of water - urban, energy and tourism - are imposing further challenges for meeting ecosystem services (Hoff, 2010) and increasing conflicts among the affected parties. Some of the potential solutions to these problems - such as changes in infrastructure or limitations of irrigation - are not accepted by all social sectors. Water resource managers face the challenge of ensuring the future sustainability of water resources while maintaining strategic agricultural, social and environmental targets. Climate change imposes an additional challenge, and understanding its implications and policy requirements is a complex process, as we shall see.

\subsection{The need for re-thinking water policy priorities}

Under climate change, policies need to keep in mind the different variations within regional climate. This is particularly true in the European context where regional directives need to be sensitive to the differences between arid Mediterranean climates and northem or central European areas with greater water availability. Finding common ground between these competing regional claims is a serious challenge to regional policy development. Nevertheless, it is a challenge that needs to be addressed to ensure the coherence and efficiency of policy measures under a changing climate.

The European Union over the past decade has been facing this challenge in a proactive manner. EU water policy is contained under the overarching Water Framework Directive (WFD, 2000). The directive consists of an extremely well developed and comprehensive set of policies although a few aspects remain a challenge in some areas (Hering et al., 2010; Rossi, 2009). The directive aims to ensure proper management

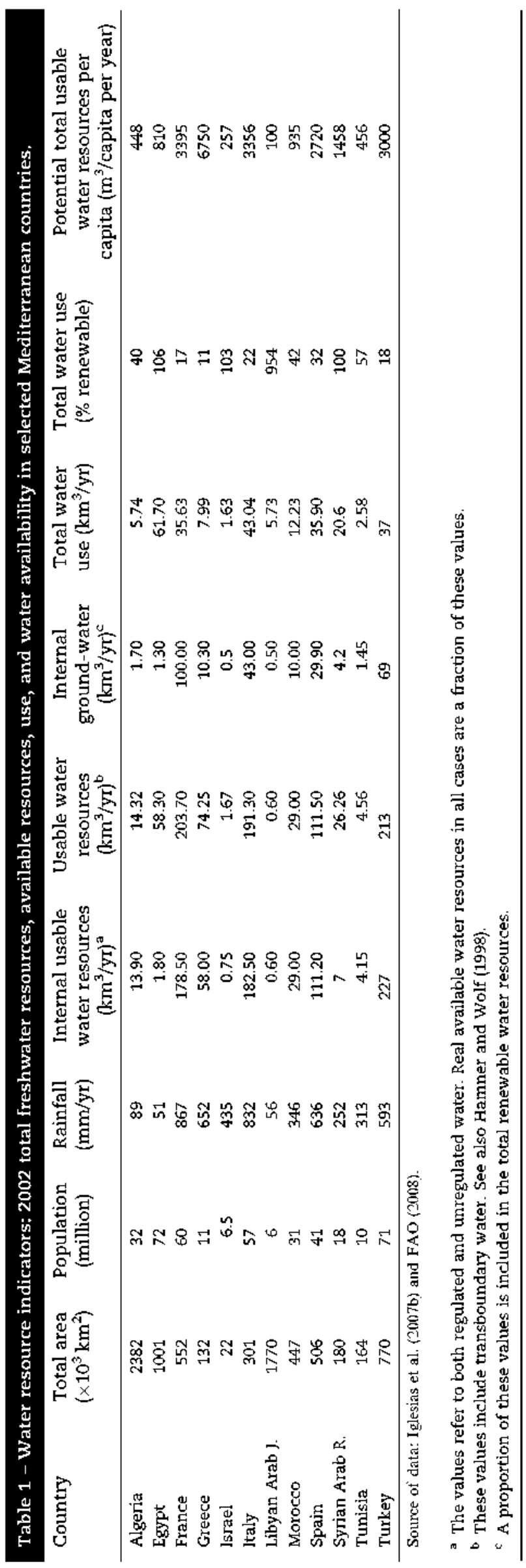


of water resources under ever-growing demand as a way of ensuring the "good status" of all water bodies. The Common Implementation Strategy (CIS) was developed to create a uniform approach for the application of the WFD by ensuring that the same priorities are set for all member states, provide informal technical guidance and create a common pool of knowledge and past experiences. In a critical review of the WFD's achievements Hering et al. (2010) state that the framework "changed water management in all member states of the EU fundamentally, putting aquatic ecology at the base of management decisions". This paradigm shift in water management has included the move from management by administrative borders to management by hydrological catchment with the goal of ensuring ecosystem integrity (Hering et al, 2010). Additionally, Rossi (2009) claims that the WFD's key principles concerning water are worth highlighting: (a) water is not a commercial product but rather a heritage; (b) water should be protected both quantitative and qualitatively; and (c) environmental policy should be damage preventing.

The ambitious nature of the WFD inevitably means that there is room for improvement. Some criticisms have been voiced concerning the WFD's ability to integrate stakeholders and ensure their participation (Videira et al., 2006), the estimation of uncertainty of assessment results and the accessibility of monitoring data (Hering et al, 2010) or the WFD's appropriateness for improving drought preparedness and mitigation (Rossi, 2009). Despite these critical voices it is clear that the ambitious and transformative principles enshrined within the WFD make the need for scientific research evident. As a way of providing an accurate scientific background for the development of policies the EU has been funding a vast number of research projects concerning water resources and climate change in Europe. The true challenge, as has been identified by Quevauviller et al. (2005), is to translate these scientific findings into policy making processes. In order to address some of these concerns, Quevauviller et al. (2005) have proposed that scientific inputs should constantly feed the environmental policy process in an attempt to keep in line with the Sixth Environmental Action Programme. To do so, he proposes the development of a science-policy interface that helps further the goals of the WFD as a knowledge-based approach to water management (Quevauviller et al., 2005). In this paper we discuss the contribution of the CIRCE project to bridging the gap between science and water policy; specifically we discuss methodological approaches to link scientific data to policy development.

\section{Objectives and components of the analysis}

The focus of this work is the Mediterranean countries. The aim is to provide answers to the following questions: How much does water management needs to adapt in view of climate change? How able are societies to adapt to these changes? We address these questions by evaluating the impacts of climate change on water resources and their management, the adaptive capacity and the policy responses. Fig. 1 summarises the methodological framework outlining the objectives and the steps in the methodology.

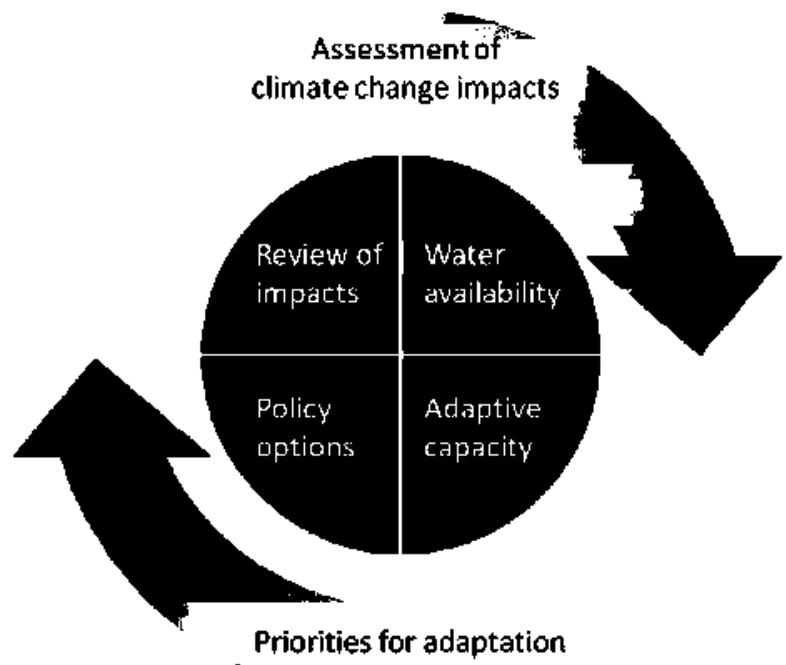

Fig. 1 - Methodological framework. Outer arrows present the objectives and inner circle shows steps in the methodology.

Quantitative indices like the ones presented in this chapter can simplify information transfer from water resource experts to policy makers. The combined analysis of these indices helps to diagnose the causes of water scarcity under different climatic conditions and to anticipate possible solutions. In a relatively large region composed of many systems, these indices may also allow for comparisons between systems to establish action priorities and budget allocation policies.

Our analysis bridges the gap between traditional impact assessment and policy formulation by directing policy attention to the causes of the water scarcity and adaptive capacity problems. Moreover we provide a platform for determining policy responses at the basin level. This evaluation helps define the sensitivity of a system to external shocks and to identify the most relevant aspects that can decrease the level of risk posed by climate change.

\section{Review of impacts}

The Mediterranean is considered to be a region that will experience large changes in climate mean and variability; that is a climate change "hot-spot" (Giorgi, 2006). Scenarios of water resources availability are developed from climate projections but need to take into water management, infrastructure and demands. Our current understanding of Mediterranean climate leads to projected overall temperature increase from 2 to $4{ }^{\circ} \mathrm{C}$ and precipitation changes of $10 \%$ to $-50 \%$ by 2080 s (Alpert et al., 2011). The changes are not equally distributed across the regions or the seasons. The changes are likely to be more pronounced in North Africa, with temperature increase that reaches $+5^{\circ} \mathrm{C}$ by the $2080 \mathrm{~s}$ in some scenarios and an alarming increase of extreme temperature (hot and very hot days); drought periods may increase throughout the Mediterranean (Giorgi and lionello, 2008; Christensen and Christensen, 2007a,b). As result, evapotranspiration rates will 
increase, soil structure changes will result in increased rates of soil erosion. Given an adequate management strategy that prioritises adaptation, climate change may also produce some positive changes in water resources for some areas. The changes may result in risks and opportunities for the water system and the environmental and social systems that depend on water.

Scenarios of water resources availability rely first on climate projections. Our current understanding of Mediterranean climate points to increases in temperature and reductions in precipitation over the next fifty years (Alpert et al., 2011). These projections may result in reductions of average annual runoff up to $50 \%$ challenging the whole socioeconomic model which is based largely on water demanding activities: recreation, tourism, and food production. The solution to those problems will imply social changes, a progressive increase of water demand management and a consensus reallocation of water availability to priontised users. The agreement on essential uses remains a controversial issue across the region. In this process, policies regulating water usage, water accessibility and hydraulic infrastructure, will play a critical role in making water available to users by overcoming the spatial and temporal irregularities of natural regimes.

Protecting the world's freshwater resources requires diagnosing threats over a broad range of scales (Vorosmarty et al., 2010) and sectors (Table 2). In the Mediterranean, climate change impacts on water will have a large impact on human water security and biodiversity (Vorosmarty et al., 2010). There are several hundred studies on the potential impacts of climate change on water resources in the Mediterranean which apply many different approaches (European Environment Agency, 2009). According to Glejck and Palaniappan (2010), more and more watersheds appear to have passed the point of "peak water", a concept related to the sustainability of water management. These studies have different focus - from ecosystems to water pricing to recreational water, a wide range of time-frames, different scenarios and spatial scales that vary from the local to the global analysis. Although the results are diverse and sometimes contradictory, a common element is that one of the primary impacts of climate change will be a reduction of water availability in the Mediterranean (European Environment Agency, 2007, 2009).

\section{Water availability \\ 4.1. Balancing water supply and demand}

All water-abstracting sectors require a reliable supply in order to provide sufficient water during periods of prolonged lack of rainfall. As a result, the storage of surface water in reservoirs is commonplace and transfers of water between river basins also occur. In addition, the artificial recharge of groundwater by river water has been a traditional means of improving supply. Finally, the production of freshwater via desalination or recycling is also playing an increasingly important role.

Alteration of hydrological regimes as consequence of climate change jeopardises equilibrium of water resources systems. The potential effect is very different depending on the regulation capacity. There are many studies of the impacts of climate change in the natural hydrological regime, but the impact in regulated systems is much less known. An analysis of climate change in regulated systems in the Mediterranean water basins would highlight the effects of adaptive regulation as management alternative. This analysis is extremely data intensive and out of the scope of this assessment. Here we provide an example in a characteristic Mediterranean basin.

Reservoir regulation has been one of the most important water resources management in Mediterranean countries and has generated significant impacts. The potential for optimal reservoir regulation as an adaptation strategy has been recognised. A reservoir is a dynamic storage of water, which can be controlled, and is used to balance the irregularity of water resources. Even though society and reservoir managers are fully aware that reservoir operation affects the environment, and that reservoir construction and structural or operational modifications of existing reservoirs are unlikely, existing reservoirs are being subjected to intense multiobjective demands - including water quality - in spite of their limited resources. Making water quality a priority requires paying close attention to current water use patterns (including

Table 2 - Climate change induced risks and opportunities and degree of expected impacts on different sectors.

\begin{tabular}{llllll} 
Description & Ecosystem & Urban sector & Rural sector & Health sector & Economic activities \\
\hline Risks & & & & & \\
Expansion of area with water deficit & High & Low & High & High & Medium \\
Increase in water demand (irrigation) & High & Low & High & High & Low \\
Increased drought and water scarcity & High & Medium & High & High & Medium \\
Increased floods & Medium & High & Medium & High & Medium \\
Water quality deterioration & High & Medium & Medjum & High & Low \\
Increased soil erosion, salinity and desertification & High & Low & High & Medium & Low \\
Loss of snow and glaciers (natural reservoirs) & High & Low & High & Medium & Low \\
Sea level rise & High & High & Medium & High & Low \\
Opportunities & & & & & Medium \\
Increased water availability & High & Medium & High & Low & High \\
Increased potential for hydroelectric power & n.a. & High & Medjum & Low & High \\
Increased potential to produce food and bio-fuels & n.a. & n.a. & High & n.a. & \\
\hline
\end{tabular}

Sources: Alcamo et al. (2007). Annell (2004), Banett et al. (2005). Blanco-Canqui et al. (2010), Copetti et al. (2010). EEA (2009). Iglesias et al. (2009). IPCC (2007), Milly et al. (2005), Parry et al. (2004), Plan Bleu (2010), Rosenzweig et al. (2004), Vorosmarty et al. (2010). Wreford et al. (2010). 
water supply, flood control, hydropower, navigation, fish and wild life conservation, and recreation). Water quality may also be considered a reservoir purpose when water is provided to assimilate waste effluents. It is not surprising then that defining optimal reservoir operation for reservoirs with multiple water uses is a challenge.Supply scenarios

Reductions of the water inflow and increase of the coefficient of variation may result in significant decreases in the water availability, between $20 \%$ and $40 \%$. This clearly demands adaptation measures that produce large social impacts. In most Mediterranean basins, where regulation capacity is almost already covered, the reductions in water availability will result in impositions of demand restrictions. The demand restrictions will have to be almost identical to the reductions in water availability.Demand scenarios

Irrigation water demand scenarios are determined by changes in the physical variables of the scenario (precipitation and temperature), changes in socio-economic conditions (management at the farm level, markets and trade, and policy), and changes in technology (agricultural and hydraulic). When policy and technology remain constant, it has been shown that agricultural water demand increases in all scenarios in the region (Iglesias et al., 2007a). The main drivers of this irrigation demand increase are the decrease in effective rainfall and the increase in potential evapotranspiration (due to higher temperature and changes of other meteorological variables). Even in basins where farmers apply efficient management practices and adjust cropping systems to the new climate, changes in policy, land use or technology will be crucial for lowering future irrigation demand and are key determinants of future projections (Iglesias, 2009). It is generally accepted that future agricultural and water policy, including water pricing and compliance with environmenta] regulations, will have a profound effect in lowering the demand of irrigation water. It is also reasonable to assume that technology will make water use more efficient. Therefore, future irrigation demand may increase or decrease as a function of policy interventions and technological developments, even if to a small degree.

Scenarios of urban water demand are driven by changes in population and lifestyles. Population is expected to increase slightly (CIESIN, 2005), projections of increased GDP result in lifestyle changes that demand more urban water (from collective living to single home living). Unless GDP grow th is decoupled from urban and industrial water use it is likely that the demands from these sectors will continue to grow.

\subsection{Water availability and policy assessment model}

The water availability and policy assessment (WAPA) mode] (Fig. 2) may be used to compute the water availability and demand-reliability curve, which provides a simple way to evaluate water availability under different policy and climate change scenarios. WAPA model architecture, system management options, system performance evaluation and demand performance analysis. The model has been applied to evaluate economic decisions of drought policy and water policy in the Mediterranean (Quiroga et al., 2011a,b). The model links water supply, demand and management allowing the analysis of policy options. The model computes water

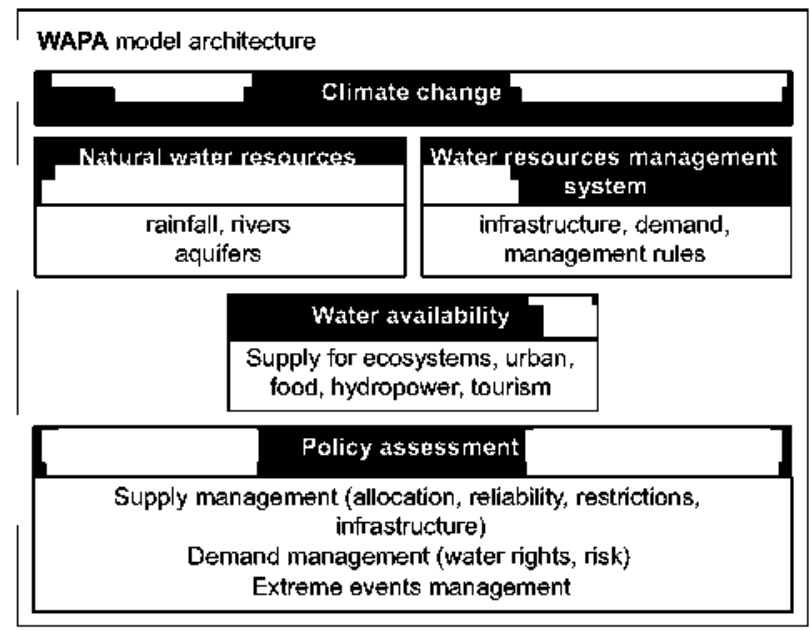

Fig. 2 - Architecture of the water availability and policy assessment (WAPA) model.

availability and reliability as result of implementing climate or policy scenarios.

As it was originally designed to calculate surface water availability, the WAPA model does not explicitly contemplate the inclusion of groundwater in its calculations. That being said, the model's results may approximate the joint extraction of surface and ground waters. In cases where only groundwater is extracted, for instance, the calculation of available water is analogous to the calculation of aquifer recharge. Also, when surface and ground waters are extracted independently (except for the case of coastal aquifers) the extraction of groundwater is subtracted from the inputs to downstream surface reservoirs. For large basins, then, the WAPA results can be considered a first estimate of the availability of surface and ground water. In its current state, the WAPA does not consider the case where ground waters are extracted to compensate for low levels of water in reservoirs.

WAPA simulates the joint operation of all reservoirs in a basin to satisfy a unique set of demands. Basic inputs to the WAPA model are the river network topology, the reservoir characteristics (monthly maximum and minimum capacity, storage-area relationship and monthly evaporation rates), the naturalized stream flow series entering different points of the river network, the environmental flow conditions downstream of reservoirs and monthly values of urban and agricultural demands for the entire basin. The model is based on the mass conservation equation, and main assumptions refer to how reservoirs are managed in the system: to supply demands for any given month, water is preferentially taken from the most downstream reservoir available, since spills from upstream reservoirs can be stored in downstream ones. In each time step, the model performs the following operations:

(1) Satisfaction of the environmental flow requirement in every reservoir with the available inflow. Environmental flows are passed to downstream reservoirs and added to their inflows.

(2) Computation of evaporation in every reservoir and reduction of available storage accordingly. 
(3) Increment of storage with the remaining inflow, if any. Computation of excess storage (storage above maximum capacity) in every reservoir.

(4) Prioritised satisfaction of demands. Use of excess storage first, then available storage starting from higher priority reservoirs. In the case of current and future water shortages, case-specific decisions will need to be made concerning the prioritisation of demands.

(5) If excess storage remains in any reservoir, computation of uncontrolled spills.

The result of the joint reservoir operation model is a set of time series of monthly volumes supplied to each demand and monthly values of stored volume, spills, environmental flows and evaporation losses in every reservoir. Reliability is computed for every demand by comparing the actual supply values during the simulation with theoretical demand values. A macro is available to repeat the computations changing values of a given demand type, which allows the computation of the demand-reliability curve.

The regulatory effect is evaluated through water availability, i.e., the maximum demand that could be potentially attended in a certain point of the fluvial network for predetermined guarantee criteria. In order to facilitate the comparison, this variable is normalized using the average annual flow in a particular point of the system. Then it is possible to evaluate the effect of climate change scenarios.

Management policies may be evaluated in WAPA by modification of different coefficients or parameters which modify system performance and create policy scenarios. Two broad policy categories may be considered: supply management, demand management (Table 3). Model data and data sources are summarised in Table 4

\subsection{Example of application in a Mediterranean basin}

The Ebro basin is representative of a medium size water unit in the Mediterranean; the system is composed of 34 rivers, 27 major reservoirs totalling $7.13 \mathrm{~km}^{3}$ of reservoir storage, an urban demand of $0.96 \mathrm{~km}^{3} / \mathrm{yr}$ and current irrigation demand of $6.35 \mathrm{~km}^{3} / \mathrm{yr}$. Climate change scenarios were generated for every streamflow point in the Ebro basin by transforming the mean and coefficient of variation of the original series as suggested by the corresponding climate projection. Environmental flows were fixed at $10 \%$ of mean annual flow in every location.

Table 5 shows estimated changes in water availability under climate change. The study first estimated changes in runoff and runoff variation under a range of climate change scenarios, then applied the WAPA model to evaluate optimal management that represents the optimal policy options with the corresponding trade-off between supply and reliability as determined by the WAPA analysis. According to the results of the climate change simulations, runoff and water levels will change significantly in the future (Fig. 3). The results are in line with the results from previous studies in the Mediterranean regions (Iglesias et al., 2007b; IPCC, 2007; European Environment Agency, 2008; Giorgi and Lionello, 2008); climate change results in a moderate increase of flood risk throughout the year and a large increase in spring and summer drought. This implies the need to establish alternative options for water management for all sectors and highlight the importance of hydrological forecast to enhance the potential for improved regulation planning.

The WAPA model is also used to evaluate the demandperformance. For example, if we consider two demand components (e.g. ecosystem services and urban) under current climate and climate change scenario, the model can help in estimating the water availability and reliability for a range of management options (Fig. 4). The analysis is performed on the climate change scenario demand component with a fixed value of current demand component. Performance values for demand components need to be taken into account.

The results depend on the risk aversion that stakeholders (water managers and users) are willing to take (Quiroga et al., 2011a). Reducing the water allocated for irrigation (Management 2) is the optimal decision, independently of the risk aversion coefficient considered. On the other hand, when stakeholders accept a certain amount of risk, reducing water reliability (Management 1) is the optimal decision. Reducing water allocation has a lower associated risk level, and would

Table 3 - Types of policies and implementation in the WAPA model,

\begin{tabular}{lll} 
Type of policy & \multicolumn{1}{c}{ Actions } & \multicolumn{1}{c}{ Implementation in WAPA (example) } \\
\hline Supply management policies & $\begin{array}{l}\text { Water allocation for environmental } \\
\text { and consumptive uses } \\
\text { Reuse of urban water }\end{array}$ & $\begin{array}{l}\text { Selected quantile of the monthly marginal distribution to } \\
\text { specify minimum environmental flow requirements } \\
\text { A coefficient for internal water reuse within cities that takes } \\
\text { into account per-capita water requirements and the return } \\
\text { and reuse coefficients } \\
\text { Reduction of water allocation for a given use can be analyzed } \\
\text { through its effect on demand reliability }\end{array}$ \\
& Reduction of water allocation & $\begin{array}{l}\text { Increase of the regulation volume available for water } \\
\text { conservation or a densification of the water distribution } \\
\text { networks }\end{array}$ \\
& $\begin{array}{l}\text { Increase water supply } \\
\text { Selected quantile of the monthly availability } \\
\text { Reduction of per-capita water requirements in the model }\end{array}$ \\
& $\begin{array}{l}\text { Increase supply efficiency } \\
\text { Reduction of per-capita or } \\
\text { per-hectare water use } \\
\text { Water rights exchange programs } \\
\text { lncrease resource efficiency }\end{array}$ & $\begin{array}{l}\text { Changes in the required performance for urban demands } \\
\text { Changes in the required performance for inigation demands }\end{array}$ \\
\hline
\end{tabular}


Table 4 - Data and data sources used in the water model.

\begin{tabular}{|c|c|c|}
\hline Type of data & Purpose & Source \\
\hline Topology & Geographical units analysis (sub-basins) & Hydro1k data set \\
\hline Naturalised streamflow & $\begin{array}{l}\text { Naturalized streamflow. Since runoff obtained } \\
\text { from regional climate models usually presents } \\
\text { significant bias, average values of composite } \\
\text { runoff from UNH/GRDC were used; these values } \\
\text { combine observed river discharges with a water } \\
\text { balance model }\end{array}$ & $\begin{array}{l}\text { Regional climate models (e.g. PRUDENCE (Christensen } \\
\text { and Christensen, 2007a,b), baseline (1960-1990) and } \\
\text { future projections (2007-2010) (Fronzek and Carter, 2007). }\end{array}$ \\
\hline Regulation & $\begin{array}{l}\text { Storage volume available for regulation in every } \\
\text { sub-basin: Reservoir location, storage capacity. } \\
\text { flooded area }\end{array}$ & ICOLD World Register of Dams (ICOLD, 2003) \\
\hline Evaporation losses & Evaporation losses from reservoirs & $\begin{array}{l}\text { Computed from the evaporation output of the } \\
\text { regional climate models }\end{array}$ \\
\hline Environmental flows & $\begin{array}{l}\text { Monthly minimum required environmental flow. } \\
\text { Defined as a given quantile in the distribution } \\
\text { of naturalized monthly flows. }\end{array}$ & Computed through hydrologic methods \\
\hline Urban demands & $\begin{array}{l}\text { Population and per-capita water requirements. } \\
\text { Average return flows from urban demands } \\
\text { are estimated as a function of per-capita } \\
\text { water requirement. }\end{array}$ & $\begin{array}{l}\text { Sub-basin population from the Global Rural-Urban } \\
\text { Mapping Project (CIESIN, 2005). Per-capita water } \\
\text { requirement (Plan Bleu) }\end{array}$ \\
\hline Irrigation demands & $\begin{array}{l}\text { Potential irrigation area and per-hectare water } \\
\text { requirement. }\end{array}$ & $\begin{array}{l}\text { Potential irrigation area was obtained from the FAO } \\
\text { and Plan Bleu. Average return flows from irigation } \\
\text { demands are estimated as a function of per-hectare } \\
\text { water requirement. }\end{array}$ \\
\hline
\end{tabular}

therefore be preferred by managers that are more risk averse. Reducing water reliability has a higher associated risk leve] and would therefore be preferred by those less risk averse. The results show that there is no optimal policy response and that this is highly dependent on the scenario considered and the willingness of the stakeholders to accept risk.

\section{Adaptive capacity}

Adaptive capacity is understood as the capacity of a system to cope with or recover from a potentially damaging change in climate conditions. In that sense, adaptive capacity is the combination of a number of social and economic components (Yohe et al., 2006; Iglesias et al., 2010; IPCC, 2007). Here we compute an adaptive capacity index that integrates determinants of policy in a country or region, based on the aggregate social, economic, technological, environmental, and climate components of adaptive capacity (Iglesias et al, 2007a). The value of the index for a system represents its potential adaptive capacity, understood as a modifier of climate impacts. Social characteristics depend to a large extent on the type of policies implemented in the country or region and they determine the degree of social adaptive capacity to climate change; here water policies are explicitly considered. The level of economic development is an indicator of the capacity of a country to invest in development technologies, food security and income stabilization. The efficiency in the use of resources for production and the adoption of new technologies significantly increases a system's adaptation potential. The climate capita] represents the baseline state conditions that are not modified in the short term. Finally to quantify the index we: (a) select indicators that are policy relevant; (b) normalize the indicators with respect to a common baseline; (c) combine the subcomponent indicators within each policy category by weighted averages; and (d) quantify adaptive capacity index as the weighted average of the components.

Fig. 5 shows the global values of the adaptive capacity index for seven Mediterranean countries. The evaluation of adaptive capacity at country level hides important regional disparities.

Table 5 - Simulation of water availability in the Ebro water unit under different management alternatives in the current climate.

\begin{tabular}{|c|c|c|}
\hline Type of management & Variable & Value \\
\hline \multirow[t]{4}{*}{ Current management } & Annual streamflow mean $\left[\mathrm{hm}^{3} / \mathrm{yr}\right]$ & $16,921.78$ \\
\hline & Annual streamflow Coefficient Var. & 0.27 \\
\hline & Storage volume $\left[\mathrm{hm}^{3}\right]$ & 7276.00 \\
\hline & Water availability $\left[\mathrm{hm}^{3} / \mathrm{yr}\right]$ & 2928.31 \\
\hline \multirow{3}{*}{$\begin{array}{l}\text { Simulated effect of management alternatives that imply } \\
\text { no further expansion of infrastructure (effects of optimal } \\
\text { reservoir management) }\end{array}$} & $\begin{array}{l}\text { Water availability in the "Local management" } \\
\text { alternative }\left[\mathrm{hm}^{3} / \mathrm{yr}\right]\end{array}$ & 9401.56 \\
\hline & $\begin{array}{l}\text { Water availability in the "Large distribution networks" } \\
\text { management alternative }\left[\mathrm{hm}^{3} / \mathrm{yr}\right]\end{array}$ & $11,173.11$ \\
\hline & $\begin{array}{l}\text { Water availability in the "Global management" } \\
\text { management alternative }\left[\mathrm{hm}^{3} / \mathrm{yr}\right]\end{array}$ & $11,464.45$ \\
\hline
\end{tabular}




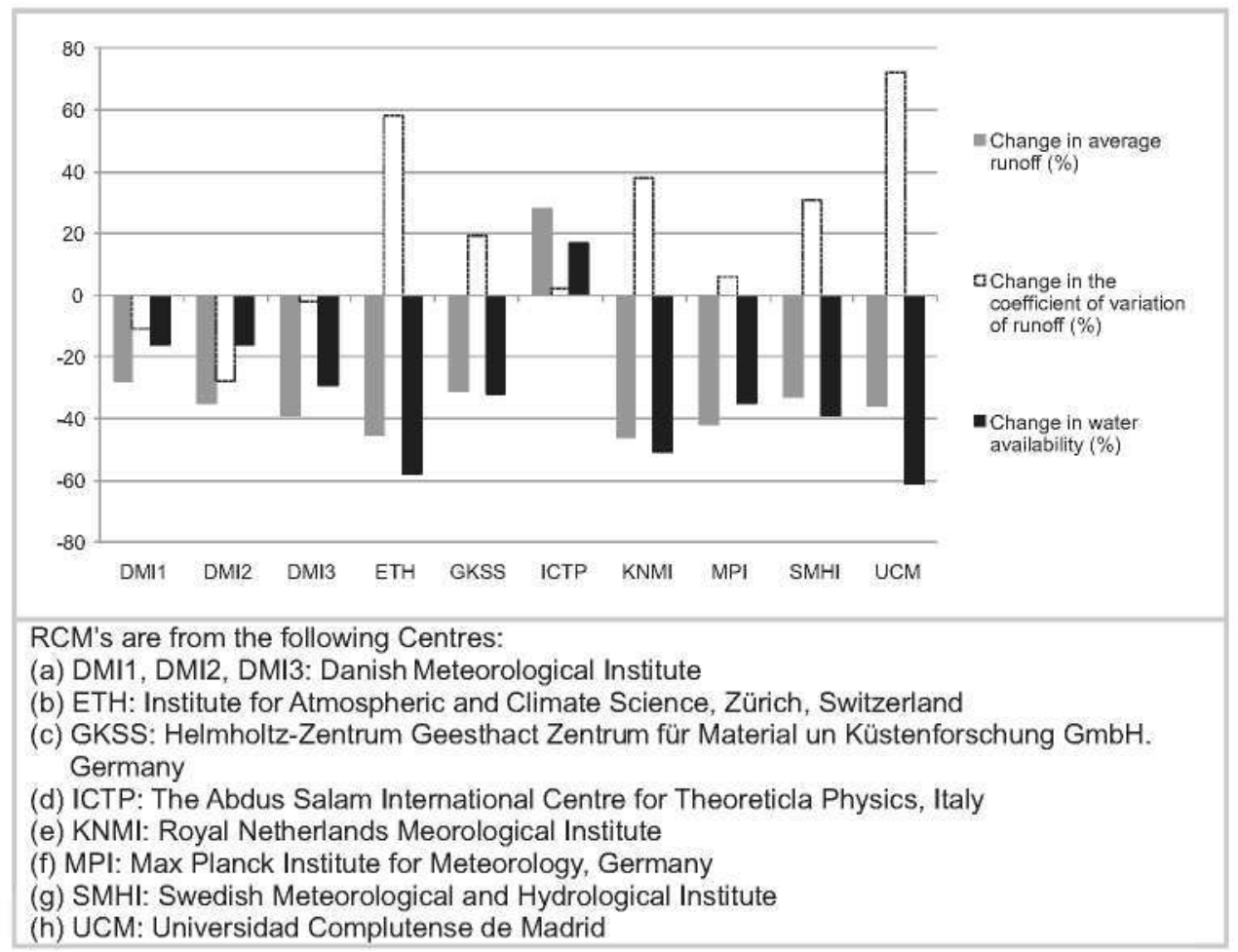

Fig. 3 - Percent change from baseline in average runoff, coefficient of variation of runoff and water availability by 2080 s in Ebro Basin driven by the Hadley Centre GCM HadAM3H under A2 SRES scenario and using different RCMs.

However, considering that policies to facilitate adaptation are often initiated, or promoted at the national level and financing may come from central government, it allows us to obtain an approximation of the overall capacity of a country as to adapt. Further studies could focus on evaluating adaptive capacity at lower spatial scales, such as the river basin level. This will undoubtedly depend on the availability of data at this level of analysis - which still presents a bottleneck to modeling and evaluating in many different fields. This may be particularly difficult for settings outside of the European Union and other OECD countries where data may be lacking or inexistent and where, arguably, the evaluation of adaptive capacity and the identification of sources of vulnerability is most valuable.

The scores of the adaptive capacity index range on a scale of 0 to 1,0 being the situation where adaptive capacity is least

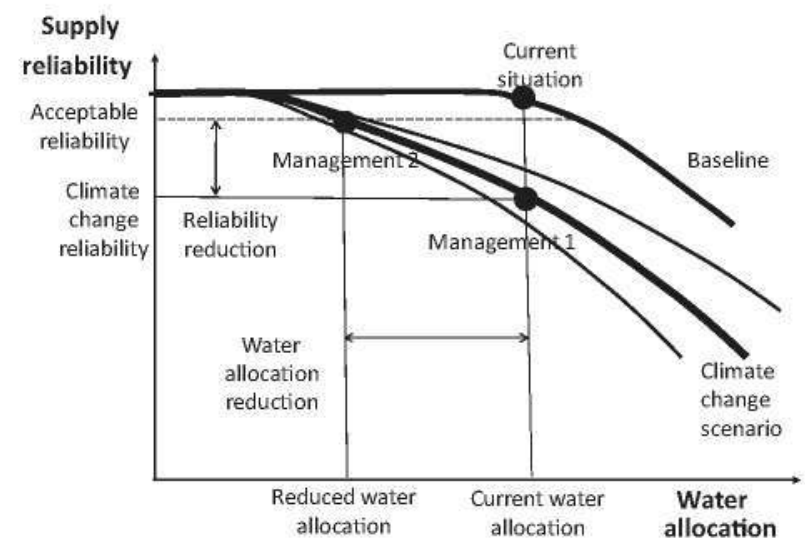

Fig. 4 - Performance of indicators. developed and 1 where adaptive capacity is most developed. The total index is generated as the average of all components. The final value of the index depends on the valuation of each of the component. By looking at the components of adaptive capacity that limit the overall value, the analysis may assist in the formulation of adequate policies to respond to climate change. This difference is especially evident in the case of economic and social capacities (Iglesias et al., 2009).

Here we present the results of the index under a single scenario, where all components are valued equally. Ideally, the weighting of the components would be adjusted for each country or region to reflect the exact importance of each for the particular level of analysis. This however is beyond the scope of the present study and would make inter-country or region comparison more difficult. Especially when making future projections, weighting difficulties could help to evaluate different routes of development. For example, a plausible scenario may give the social component an additional weight, reflecting the assumption that a society with institutional coordination and strengths for public participation is less vulnerable to climate change. Again, the difficulty in obtaining data for future projection at the national, regional or subregional level may present an obstacle to evaluating different future scenarios.

\section{Insights for water policy under climate change}

Policy is deeply involved in the water sector. Usually, policy development is based on historical analysis of water demand 


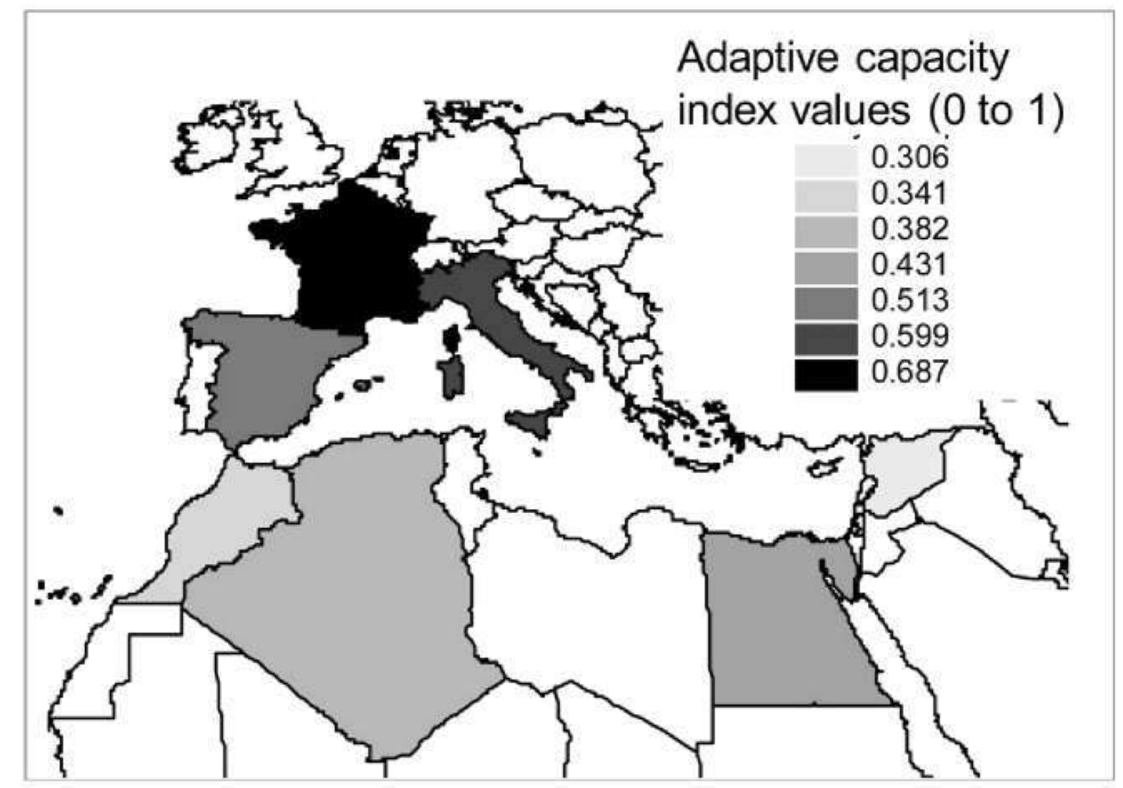

Fig. 5 - Adaptive capacity index for selected Mediterranean countries.

and supply. It is therefore a challenge to develop policies that respond to an uncertain future.

In this chapter we have attempted to face part of this challenge by presenting an approach that assesses how people - society and policy - may influence water in the Mediterranean under climate change. We have also shown how an estimation of adaptive capacity evaluates the extent to which a system can respond to climate change. Together - the assessment of water risks and adaptive capacity - may be useful in singling out areas of potential water stress and conflict. This information may be used to implement and develop policy. Here we present a simple characterisation of water scarcity to define broad policy thresholds. With these thresholds we then formulate a few policy recommendations.

\subsection{Policy options and thresholds}

Here we summarise a diagnostic tool to identify and evaluate climate change adaptation policies in areas of water scarcity based on the indices of water scarcity developed by MartinCarrasco and Garrote (2007). The methodological framework comprises a set of three indices, described below, that must be used jointly to quantify the severity of potential water scarcity problems in a system, its causes, and possible solutions. The indices are numerical index values that are classified in qualitative categories: (a) water scarcity index (SI) evaluates the system's capacity to supply its demands; (b) demand reliability index (RI) quantifies the system's reliability to satisfy demands; and (c) potential for more infrastructure index (II) evaluates the natural resources available for development in the system.

Fig. 6 shows how the intensity of water scarcity problems in water resources systems can be characterised through a combined analysis of the water scarcity index and the demand reliability index (Martin-Carrasco and Garrote, 2007). In the figure, demand reliability index (defined as the supply served with acceptable reliability divided by total demand) cannot be greater than demand satisfaction index (defined as the total supply divided by total demand) because, by definition, supply served with acceptable reliability must be less than total supply. The thresholds that define water scarcity problems are case-specific and therefore not absolute values since they are determined by country-specific water management policies and environmental conditions. In Martin-Carrasco and Garrote (2007) the thresholds are defined for the Ebro basin by creating intervals for the demand reliability and demand satisfaction index values. These intervals can greatly facilitate the characterisation of water scarcity problems in any system and are therefore the first step in the policy intervention process.

A combined analysis of the indices is proposed to diagnose water management problems and the reliability and vulnera-

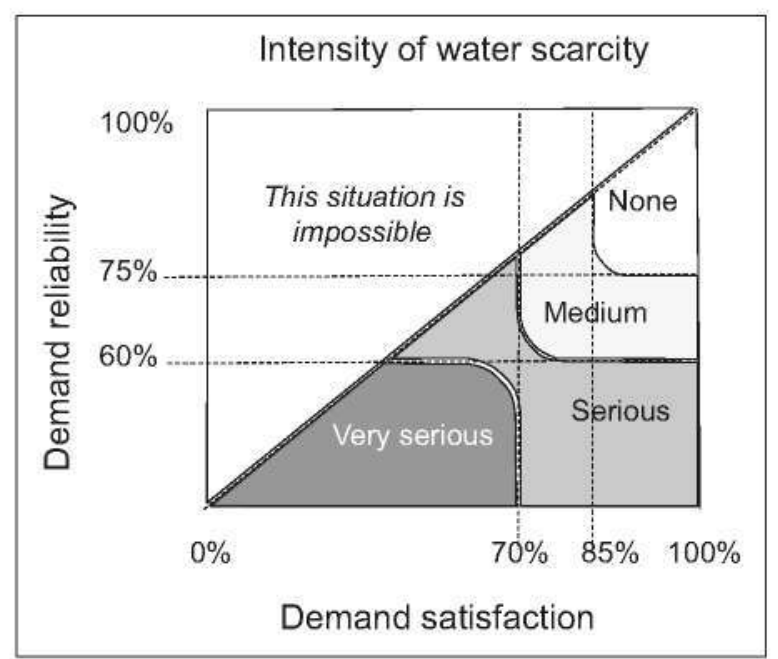

Fig. 6 - Intensity of water scarcity problems and thresholds of demand reliability and satisfactions. 


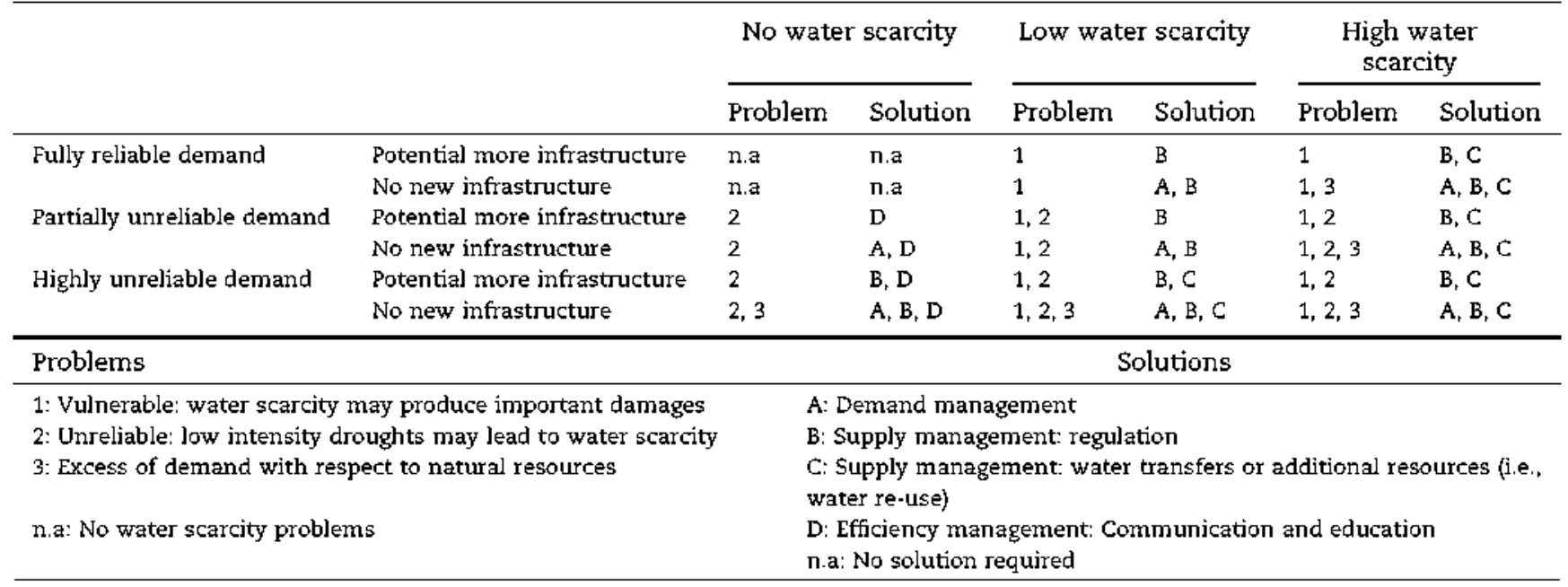

bility of systems under climate change scenarios and to identify public policies to recover equilibrium between water supply and demand. The indices may also be used to evaluate the effectiveness of climate change adaptation policies in the water sector. In general, systems with high water scarcity require actions that increase available resources. Systems with low demand reliability generally require structural actions to consolidate water supply to demands or nonstructural actions to mitigate drought impacts. When these problems coincide with low values of potential infrastructure development, actions should focus on the demand side, trying to improve water conservation by reducing losses, increasing water efficiency, encouraging water recycling, and making different demands compatible. Table 6 shows how the characterisation of water scarcity problems can be combined with broad categories of policy solutions. Each category of policy solution proposes the utilisation of different tools that target different user groups in order to tackle the problem of water scarcity flexibly.

\subsection{From index thresholds to policy recommendations}

The effect of water policy decisions may be evaluated by considering the resulting water availability for nature and non-nature use. Fig. 7 outlines how policy interventions may modify water for nature and for non-nature uses. Water allocation for environmental and consumptive uses is an essential policy (type B in Fig. 7). Policy makers establish the criteria to authorize water abstractions from rivers based on the environmental conditions that should be respected for natural ecosystems. In the past, little attention was paid to environmental status of water bodies, and abstractions were usually approved even if there was no minimum environmental flow specified. Recently, the Water Framework Directive has placed emphasis on environmental status, and therefore strict control is placed on environmental flows before water abstractions are authorized.

The reuse of urban water may be included in a group of policies (types A, C and D in Fig. 7) that will need to become increasingly important since future scenarios project higher population and per-capita water requirement. Other demand side policies could make use of appropiate water pricing mechanisms, investments in technology to improve efficiency, upgraded distribution networks and making sure that agricultural subsidies are linked to efficient use (European Environment Agency, 2009). Efficiency policies may play a major role for improvingmanagement (type D in Fig. 7). For example reduction of per-capita or per-hectare water use that always results in an increase of water availability and reliability.

A number of policies may be implemented to overcome temporary water deficits. Water rights exchange programs (type A in Fig. 7) may be implemented to overcome temporary deficits and to increase system performance. Proactive drought management measures to increase drought resilience may include improved performance for irrigation demands (types A and D in Fig. 7). Policies that foster communication and education are also since it has been shown that joint participative knowledge is an important factor in facilitating efficient water management (Huntjens et al., 2010).

Finally, policies may seek to increase water supply (types B and $C$ in Fig. 7) by effectively increase the regulation volume available for water conservation or a densification of the water distribution networks. Among other measures this may

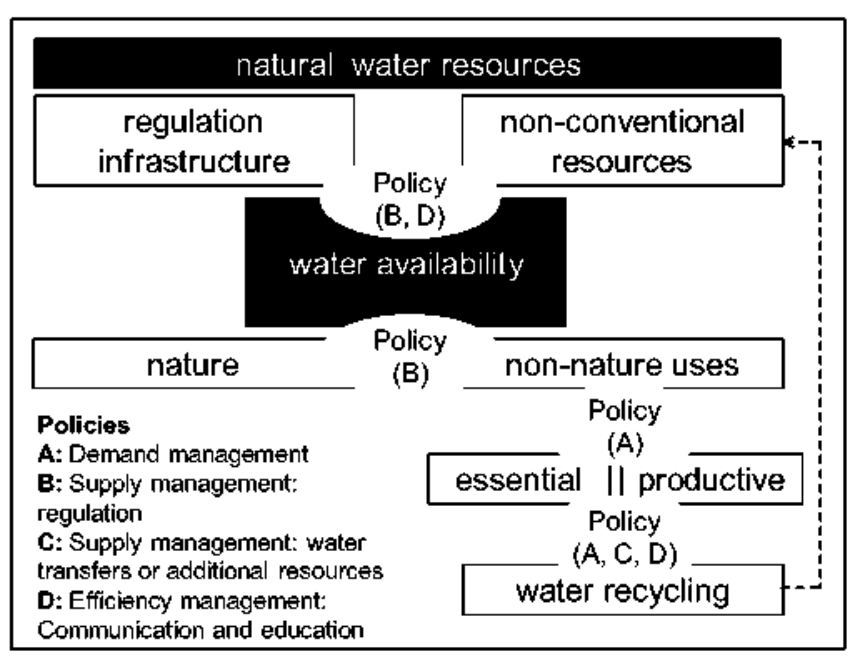

Fig. 7 - Role of policy interventions on the water sector. 
include water recycling and desalination (European Environment Agency, 2009).

\subsection{Integrating water policy priorities}

Early on we noted the need for developing an approach to water-policymaking that is nuanced and makes room for regional variations in climate and in socio-economic contexts. Indeed, science-policy integration is one of the most complex challenges that scientific and policy making communities face in that in involves knowledge sharing and exchange among a wide range of disciplines and actors (Quevauviller et al, 2005). Despite the challenge, it is possible to achieve this goal. For instance, the collaborative governance water programme in California is perhaps the most ambitious experiment in collaborative environmental policy and adaptive management in the world to date (Kallis et al., 2009).

The methodology presented here is suited to some aspects of policy development required by the WFD and the CIS as we]l as other policy contexts of the Mediterranean because it acknowledges socio-economic differences as well as levels of water scarcity both of which are important in developing the kind of management structure required. The methodology can also easily assess the viability of policies that follow the key principles of integrated water management (such as appropriate water pricing, river basin management, public participation, coordination of objectives, or good status of water bodies), enshrined in the EU within the context of the WFD, based on their relevance for the different kinds of water scarcity and social scenarios.

The methodology proposed here complements water policy developments since it is an appropriate tool for policy assessment and policy formulation. By providing an analysis of water scarcity levels and socio-economic features, the methodology may complement the CIS in the EU and other international policies by providing scientifically grounded flexibility to policy development. This is because the methodology acknowledges that water resources vary in different climate zones and that the kinds of policies that these zones require will also vary correspondingly.

Table 7 summarises a few policy suggestions derived from the scientific indicators as they have been presented in this paper. The suggested policies are far from comprising an exhaustive list, nor are they to be taken as a set menu of policies. Rather they are meant to reflect the kind of policies that may be appropriate for redressing weaknesses in adaptive capacity where water scarcity is a problem. For instance, in countries with considerable social and economic inequality and where water scarcity is not as pressing an issue, water management policies should focus on ensuring equitable access for disadvantaged populations to guarantee health and economic benefits. These types of measures are primarily concerned with managing the supply of water in a way that maximises equality. However, in the same country if water scarcity becomes a serious problem, it is likely that emergency actions will have to be enacted to prioritise certain water users over others. In such a situation, it is important to ensure that these emergency actions do not aggravate pre-existing socio-economic inequalities. This requires enforcing water regulations and transfers to guarantee the equitability of supply as well as ensuring that demands do not becomeexcessive. The suggested policy mechanisms are in line with key priorities in European and international water policy and are based on the concept of integrated water management which is concerned with ensuring that all of a region's water resources are efficiently managed while making room for social and environmenta]

\section{Table 7 - Summary of some policy suggestions derived from the scientific indicators.}

\begin{tabular}{|c|c|c|c|}
\hline $\begin{array}{l}\text { Water scarcity levels } \\
\text { defined by indicators }\end{array}$ & $\begin{array}{l}\text { Weakest component of } \\
\text { the adaptive capacity }\end{array}$ & $\begin{array}{c}\text { Type of policy intervention } \\
\text { required }\end{array}$ & Appropriate policy mechanisms \\
\hline \multirow[t]{3}{*}{ Low to medium } & Social and economic factors & Supply management & $\begin{array}{l}\text { Infrastructure investments, ensure } \\
\text { access to sanitary and safe water } \\
\text { sources, development of institutional } \\
\text { and organisational capacity for water } \\
\text { management }\end{array}$ \\
\hline & $\begin{array}{l}\text { Technological eco-efficiency } \\
\text { and natural capital }\end{array}$ & $\begin{array}{l}\text { Demand management, Supply } \\
\text { management (regulation) }\end{array}$ & $\begin{array}{l}\text { Design of system for water rights } \\
\text { trading, appropriate water pricing } \\
\text { policies and efficiency incentives }\end{array}$ \\
\hline & Climate & Extreme event management & $\begin{array}{l}\text { Consultation on perception and } \\
\text { appropriate response to potential } \\
\text { climate impacts - design of policies } \\
\text { and priorities of water provisioning } \\
\text { in emergencies }\end{array}$ \\
\hline \multirow[t]{3}{*}{ Serious to very serious } & Social and economic factors & $\begin{array}{l}\text { Supply management (transfers } \\
\text { and regulation) Demand } \\
\text { management }\end{array}$ & $\begin{array}{l}\text { Guarantee that water-pricing and } \\
\text { efficiency policies do not } \\
\text { disproportionately affect poor }\end{array}$ \\
\hline & $\begin{array}{l}\text { Technological eco-efficiency } \\
\text { and natural capital }\end{array}$ & Demand management & $\begin{array}{l}\text { Mandatory minimum efficiency } \\
\text { standards, ensure balance between } \\
\text { economic sectors and environmental } \\
\text { flow. }\end{array}$ \\
\hline & Clímate & $\begin{array}{l}\text { Extreme events management } \\
\text { Demand management (transfers } \\
\text { and regulation) }\end{array}$ & $\begin{array}{l}\text { Implementation of policies for } \\
\text { extreme events, water rights trading } \\
\text { and reallocation to priority sectors }\end{array}$ \\
\hline
\end{tabular}


concerns to ensure that water use is sustainable. The appropiate policy mechanisms follow from the kinds of policy interventions that are required as determined by a combined analysis of water scarcity levels and weaknesses in adaptive capacity.

\section{Conclusions}

This paper shows that policies need to be successfully balanced to achieve a true integrated water resources management, which will require striking a balance between human resource use and ecosystem protection. This is no surprise (Vorosmarty et al., 2010) but has special relevance in the Mediterranean where water policies are often centuries old and socially embedded. The reality of climate changes renders it impossible to use the past as an indicator for the future. In this assessment we find reasons to be optimistic given the important role that science and technology will play in increasing adaptive capacity and improving water accessibility. There are, however, also reasons to be pessimistic. It remains to be seen whether the current inequalities that exist in the Mediterranean will be successfully redressed given the high costs associated with technology transfer for less advantaged regions and countries.

The recent past has demonstrated a high sensitivity of water resources to changes in climate and the resulting effects on the social system. Adaptation planning is inherently challenging and often, restricted by a number of factors, including limitations in the participatory processes with the stakeholders that will have to adapt in the future; the exhaustive data requirements for evaluating adaptive capacity; the problems related to selecting adequate evaluation methods and criteria; difficulties in forecasting water supply and demand; and challenges in predicting the future adaptive capacity of the water system. Uncertainties in climate change science and long planning horizons add to the complexity of adaptation decision-making. A further important complication is presented by the difficulties in identifying and linking adaptation and development policies in many areas in the Mediterranean where a large proportion of the population does not have access to clean water and sanitation. The uncertainty of the cost and benefits of the various policies suggested is not addressed here; this is a shortcoming of this assessment.

Knowledge transfer to water managers and users and to sectors linked to water use (technology, energy, health, agriculture, and tourism sectors) is essential to enable adaptive action. The indirect impacts of water resources change in these other areas will have additional cumulative effects. Know]edge transfer between scientists, political decision-makers and the people directly affected by climate change is currently weak, and existing information is poorly used. One of the difficulties is the number and range of stakeholders involved. Another challenge is the inherent uncertainty in climate science and impacts projections: uncertainty can lead to confused messages and inertia, if it is not communicated in the right way.

While there is a continuing need to strengthen the climate change knowledge base (through research), improved understanding of climate change science will be insufficient on its own for adaptation policy development and to drive adaptation action. There is a complementary need to engage stakeholders, by developing suitable methodologies for assessment of impacts, vulnerabilities and planning as a pre-requisite for cost-effective adaptation.

Wider influences on water users ${ }^{*}$ behaviour, such as changes in demand and tariffs, must be considered alongside climate change. It is important to consider whether adaptations are sustainable, or rendered irrelevant by other sectoral drivers. This holistic approach should also ensure that adaptation decisions and investments are both cost-effective and proportionate to the risks or benefits that may be incurred.

The development of adaptation measures must take into account future socio-economic scenarios as well as future climate change scenarios. Practitioners need to understand the relevance of a future climate to a future society, rather than to society today. Credible socio-economic scenarios are required to provide a framework for adaptation decision-making for practitioners.

With so many competing pressures and drivers, and so many contributing factors to consider, not only in understanding the impacts of climate change, but also in developing adaptation options, it is likely that the role of training and advice facilities for the users and suppliers of water could become more important. While there may be many simple adaptation measures that could theoretically be introduced to address a particular risk or opportunity, these may only be practically possible under certain circumstances. For example, improving efficiency of irrigation or introducing water metering may only be options for societies that already have an understanding of alternative technologies, and who know how to encourage implementation.

A final challenge for consideration is that of finance. Many potential adaptation options are low-cost and technically manageable by individual water managers. However there are also adaptations that require large scale and long-term effort, either in water district management or in infrastructure development. In order for policy to be able to consider and take up such options, it may be necessary for financial support mechanisms to be made available.

The approach to impacts and adaptation developed in this study has provided options for wide-ranging problem. However, adaptations often involve combined effort across many sectors. Water resources are sensitive to the responses in many sectors; particularly agriculture, tourism and biodiversity conservation, and so adaptation measures for water will be strongly influenced by policies in other sectors.

Adaptation is unlikely to be facilitated through the introduction of new and separate policies, but rather by the revision of existing policies that currently undermine adaptation and the strengthening of policies that currently promote it. If adaptation is to become "mainstreamed", it will be necessary for relevant policies, such as the CAP and the Water Framework Directive to address the issue more directly.

\section{REFEREN CES}

Alcamo, J., Floerke, M., Maerker, M., 2007. Future long-term changes in global water resources driven by socio-economic and climatic changes. Hydrological Sciences 52 (2), 247-275. 
Alpert, P., Hemmings, D., Jin, F., Kay, G., Kitoh, A., Mariotti, A., 2011. The hydrological cycle of the Mediterranean. Regional Assessment of Climate Change Impacts in the Mediterranean Part 2 (Chapter 1).

Arnell, N.W., 2004. Climate change and global water resources: SRES emissions and socio-economic scenarios. Global Environmental Change 14 (1), 31-52.

Barnett, T.P., Adam, J.C., Lettenmaier, D.P., 2005. Potential impacts of a warming climate on water availability in snowdominated regions. Nature 438 (7066), 303-309.

Blanco-Canqui, H., Lal, R., Blanco-Canqui, H., Lal, R., 2010. Climate Change and Soil Erosion Risks. Springer, Netherlands.

Center for International Earth Science Information Network (CIESIN), Columbia University, Centro Internacional de Agricultura Tropical (CIAT), 2005. Gridded Population of the World Version 3 (GPWv3). Socioeconomic Data and Applications Center (SEDAC), Columbia University, Palisades, NY Available at http://sedac.ciesin.columbia.edw/ gpw.

Christensen, J.H., Christensen, O.B., 2007a. A summary of the PRUDENCE model projections of changes in European climate by the end of this century. Climatic Change $81,7-30$.

Christensen, J.H., Christensen, O.B, 2007b. A summary of the PRUDENCE model projections of changes in European climate by the end of this century. Climatic Change 81, 3-7.

Copetti, D., Carniato, L., Crise, A., Guyennon, N., Palmeri, L., Pisacane, G., Struglia, M.V., Tartari, G., 2010. Impacts of climate change on water quality. Regional Assessment of Climate Change Impacts in the Mediterranean Part 2 (Chapter 3).

European Environment Agency (2007) Climate change and water adaptation issues. EEA Technical Report No. 2/2007, 110 pp.

European Environment Agency, 2008. Impacts of climate change in Europe: an indicator based report. EEA Report 4, 2008. Available at www.eea.europa.eu/publications/ eea_report_2008_4.

European Environment Agency, 2009. Water resources across Europe-confronting water scarcity and drought. EEA Report No 2/2009. Available at http://www.eea.europa.eu/ publications/water-resources-across-europe.

FAO, 2008. AQUASTAT Database Collections. In: Internet: http $/ /$ www.fao.org, Food and Agriculture Organization of the United Nations, Rome, Accessed October 2009.

Fronzek, S., Carter, T, 2007. Assessing uncertainties in climate change impacts on resource potential for Europe based on projections from RCMs and GCMs. Climatic Change 81, 357-371.

Giorgi, F., Lionello, P., 2008. Climate change projections for the Mediterranean region. Global and Planetary Change 63, 90104.

Giorgi, F., 2006. Climate change hot-spots. Geophysics Research Letters 33, L08707 doi:10.1029/2006GL025734.

Gleick, P., Palaniappan, M., 2010. Peak water limits to freshwater withdrawal and use. Procceedings of National Academy of Sciences 1004812107v1-1004812107v18.

Hamner, J., Wolf, A., 1998. Patterns in intemational water resource treaties: the transboundary Freshwater Dispute Database. Colorado Journal of International Environmental Law and Policy 1997. Yearbook, 1998.

Hering, D., Borja, A., Carstensen, J., Carvalho, L., Elliott, M., Feld, C.K., Heiskanen, A., Johnson, R.K., Moe, J., Pont, D., Solheim, A.L., nd De Bund, W.V., 2010. The European Water Framework Directive at the age of 10: a critical review of the achievements with recommendations for the future. Science of the Total Environment 408 (19), 4007-4019.

Hoff, H., 2010. Vulnerability assessment of ecosystem services in the Mediterranean region to climate changes in combination with other pressures. Regional Assessment of
Climate Change lmpacts in the Mediterranean Part 3 (Chapter 1).

Huntjens, P., Pahl-Wostl, C., Grin, J., 2010. Climate change adaptation in European river basins. Regional Environmental Change $10,263-284$.

ICOLD, 2003. World Register of Dams. Available at http:// www.icold-cigb.net/.

Iglesias, A., Cancelliere, A., Cubillo, F., Garrote, L., Wilhite DA, 2009. Coping with Drought Risk in Agriculture and Water Supply Systems: Drought Management and Policy Development in the Mediterranean. Springer, The Netherlands.

Iglesias, A., Garote, L., Flores, F., Moneo M, 2007a. Challenges to manage the risk of water scarcity and climate change in the Mediterranean. Water Resources Management 21 (5). 227-288.

Iglesias, A., Mougou, R., Moneo, M., 2007b. Adaptation of Mediterranean agriculture to climate change. In: Battaglini, A. (Ed.), Key vulnerable Regions and Climate Change. European Climate Forum, Germany.

Iglesias, A., 2009. Policy Issues Related to Climate Change in Spain. In Policy and Strategic Behaviour in Water Resource Management by Ariel Dinar and Jose Albiac. Earthscan, London.

Iglesias, A., Mougou, R., Moneo, M., Quiroga, S., 2010. Towards adaptation of agriculture to climate change in the Mediterranean. Regional Environmental Change 11 (Suppl. 1), 1-8.

IPCC, 2007. Climate Change 2007: Fourth Assessment Report of the Intergovernmental Panel on Climate Change. Cambridge University Press, Cambridge.

Kallis, G., Kiparsky, M., Norgaard, R., 2009. Collaborative governance and adaptive management: lessons from California's CALFED Water Program. Environmental Science \& Policy 12 (6), 631-643.

Martin-Carrasco, F., Garrote, L., 2007. Drought-induced water scarcity in water resources systems. In: Vasiliev, O.F., van Gelder, P.H.A.J.M., Plate, E.J., Bolgov, M.V. (Eds.), Extreme Hydrological Events: New Concepts for Security - ISBN 9781-4020-5739-7. NATO Science Series, vol. 78, Part 4.. pp 301311. DOI: $10.1007 / 978-1-4020-5741-0 \_2$.

Milly, P.C.D., Dunne, K.A., Vecchia, A.V., 2005. Global pattern of trends in streamflow and water availability in a changing climate. Nature 438 (7066), 347-350.

Plan Bleu, 2010. Economic evaluation of water demand management in the Mediterranean. Study report. Plan Bleu.

Quevauviller, P., Balabanis, P., Fragakis, C., Weydert, M., Oliver, M., Kaschl, A., Amold, G., Kroll, A., Galbiati, L., Zaldivar, J.M., Bidoglio, G., 2005. Science-policy integration needs in support of the implementation of the EU Water Framework Directive. Environmental Science \& Policy 8 (3), 203-211.

Quiroga, S., Garrote, L., lglesias, A., Fernández-Haddad, Z., Schlickenrieder, J., de Lamo, B., Mosso, C., Sanchez-Arcilla, A., 2011a. The economic value of drought information for water management under climate change: a case study in the Ebro basin. Natural Hazards and Earth Systems Sciences 11, 643-657.

Quiroga, S., Fernández-Haddad, Z, lglesias, A., 2011b. Crop yields response to water pressures in the Ebro basin in Spain: risk and water policy implications. Hydrology and Earth System Science 15, 505-518, doi:10.5194/hess-15505-2011.

Raskin, P., Gleick, P.H., Kirshen, P., Pontius Jr, R.G., Strzepek, K., 1997. Comprehensive Assessment of the Freshwater Resources of the World. Stockholm Environmental Institute, Sweden, Document prepared for UN Commission for Sustainable Development 5th Session 1997.

Rosenzweig, C., Strzepek, K.M., Major, D.C., Iglesias, A., Yates, D.N., McCluskey, A., Hillel, D., 2004. Water resources for 
agriculture in a changing climate: intemational case studies. Global Environmental Change 14 (2004), 345-360.

Rossi, G., 2009. EU Policy for improving drought preparedness and mitigation. Water International 34 (4), 441-450.

Videira, N., Antunes, A., Santos, R., Lobo, G., 2006. Public and stakeholder participation in European water policy: a critical review of project evaluation processes. European Environment 16, 19-31.

Vorosmarty, C.J., McIntyre, P.B., Gessner, M.O., Dudgeon, D., Prusevich, A., Green, P., Glidden, S., Bunn, S.E., Sullivan, C.A., Liermann, C.R., Davies, P.M., 2010. Global threats to human water security and river biodiversity. Nature 467 (7315), 555561.

WFD, 2000. Water Framework Directive, Directive 2000/60/EC of the European Parliament and of the Council establishing a framework for the Community action in the field of water policy (EU Water Framework Directive, WFD).

Wreford, A., Moran, D., Adger, N., 2010. Climate Change and Agriculture: Impacts Adaptation and Mitigation. OECD, Paris.

Yang, H., Zehnder, A.J.B., 2002. Water scarcity and food import: a case study for Southem Mediterranean countries. World Development 30 (8), 1413-1430.

Yohe, G., Malone, E., Brenkert, A., Schlesinger, M., Meij, H., Xing, $X ., 2006$. Global distributions of vulnerability to climate change. Integrated Assessment Journal 6 (3), 35-44.

Ana Iglesias is a Professor of Agricultural Economics at the UPM, Spain and previously a Research Scientist at Columbia University, New York. Her research focuses on the interactions between global change, agriculture, and water. She currently leads several
EU projects related to adaptation policy. Her work has been published in over one hundred papers and she is a contributing author to the IPCC since 1995. She is currently Review Editor of the Economics of Climate Change for the IPCC.

Luis Garrote is a Professor of Civil Engineering and at the UPM and Vice Director of International Relations. He received formal training at the Massachusetts Institute of Technology, USA. His research focuses on the development of hydrological models, flood forecasting, reservoir management, and intelligent decision support systems. He has a long record of collaborations with National and Intemational Administrations and the private sector.

Agustin Diz holds a MSc in Anthropology \& Development from the London School of Economics and works as a Research Assistant at the Department of Agricultural Economics of the UPM. His current work focuses on the areas of water policy and the socio-economic impacts of climate change.

Jeremy Schlickenrieder is a Research Assistant Department of Agricultural Economics at UPM. His current $\mathrm{PhD}$ research focuses on the adaptation of water resources management to climate change.

Francisco Martín-Carrasco is a Professor of Hydraulic Engineering at the UPM and Dean for Academic Aftairs of the School of Civil Engineering. He received formal training at the Massachusetts Institute of Technology, USA. His extensive professional experience includes the development of the Ebro Basin Hydrological Plan. 